\title{
Teología de la Liberación y derechos humanos ${ }^{1}$
}

\author{
Michael F. Czerny, ${ }^{2}$ \\ IDHUCA, San Salvador.
}

Naci en lo que solía llamarse el segundo mundo; crecí, me formé y eduqué en el primer mundo; ahora vivo y trabajo en el tercer mundo. Vengo aqui desde el pequefio y pobre país de El Salvador, cuya única demanda al mundo ha sido la agonía de diez atlos de la guerra civil que está viviendo y, en realidad, muriendo. Les hablo con honda preocupación de que, mientras el segundo mundo está acercándose al primero, el tercero está asimilándose al cuarto, y pronto terminaremos sin ningún mundo.

Los "derechos humanos" y la "teología de la liberación" debieran proporcionarse alguna luz entre sí.

Los derechos humanos surgen de la herencia o tradición liberal. En el mundo de hoy donde la debilidad del liberalismo prevalece y donde el darvinismo económico y social es la única ley real de la tierra. Uno tiene la impresión de que los derechos humanos son un mercado más de la llamada libre competencia, "una forma velada de defender lo ya adquirido por el más fuerte o adquirible en el futuro por los más fuertes" 3 . Pero este engaño fundamental es el producto de una historia particular, limitada a una parte del mundo, mientras los derechos humanos gozan de bases universales y expresan deseos comunes de todas las personas del mundo4.

El espléndido logro y el constante desarrollo en los derechos humanos podría, sin embargo, quedarse al nivel de una falsa universalidad, abstracta y absoluta, en tanto que el discurso de los derechos humanos y la misma práctica de estos derechos ocurren al margen de las condiciones, circunstancias e historia reales en las que vive la gente.

Los derechos humanos pueden ser efectivos únicamente si tenemos claridad acerca de su punto de partida, el sujeto de los mismos y su meta. Su punto de 
partida es la lucha entre la vida y la muerte. Los sujetos de los derechos humanos son los oprimidos, las grandes mayorías, las minorías reprimidas. La meta es su liberación.

El Salvador cubre un área de 21,041 kilómetros cuadrados. De su escasa pero hacinada población, cerca de dos millones de personas "se las arreglan" para vivir, con un tipo de seguridad que uno podría llamar de "clase media", y dentro de este grupo, un puflado vive con riqueza y lujo. Otros dos millones viven en pobreza "técnica", esto es, con su trabajo apenas son capaces de asegurar la canasta básica de bienes y servicios: ésta es la pobreza diaria de la sobrevivencia. Finalmentc, una tercera parte, otros dos millones, viven en pobreza absoluta, incapaces de poder obtener la canasta básica de bienes y servicioss.

Aún así, El Salvador es conocido internacionalmente, no por su pobreza, sino por su guerra civil. Y aunque se trabaja con mucha dedicación para terminar este conflicto, temo que la guerra sea nuestro último eslabón de contacto con el mundo y que, una vez finalizada, El Salvador se hunda en el olvido de una pobreza indistinguible, donde todos los derechos humanos sean violados indiscriminadamente.

El Consejo Económico Latinoamericano (CELA) ha predicho que en el afto 2000, dentro de menos de diez años, la población de América Latina será aproximadamente de 500 millones de personas. De éstas, más o menos un tercio permanecerá en una relativa "clase media". Otro tercio luchará en medio de su pobreza técnica, y otro tercio padecerá de pobreza crítica o extrema.

La sección económica de la revista Time, en este caso una fuente confiable, predijo hace un anto que el $\mathbf{8 0}$ por ciento de Lalinoamérica estaba encaminándose hacia un tipo de pobreza caracterizado simplemente como "Bangladesh". Y sin embargo, en toda América, jsólo Haitr está clasificado por el Programa de las Naciones Unidas para el Desarrollo (PNUD), como perteneciente a los cuarenla y cuatro países más pobres del mundo!6.

Ambas pobrezas, la técnica y la extrema, generan el ciclo que se manifiesta en cada violación grave a los derechos humanos; me refiero al ciclo de explotación, miseria, protesta, represión, violaciones y, normalmente, violencia como respuesta. Por eso la pobreza, que es el destino de tan vasto número de personas, debe constituirse en la prioridad de los derechos humanos y debe ser el punto de partida de nuestra reflexión. Ello no significa que sea el único problema, ni quiere decir que la violaciơn de otros derechos, no directamente vinculados a la pobreza, debieran ser tolerados. Pero si significa que la pobreza es el punto de partida y, en este sentido, la prioridad.

Los derechos humanos son sólo el mínimo. Abogados, filósofos y profesionales, tal vez tienen la tendencia a elevar los derechos humanos a un concepto global, una forma de vida, una visión, una mistica. Los derechos humanos 
podrían convertirse en cualquiera de éstas cosas, pero esencialmente y primariamente son apenas un mínimo, un mínimo legal y constitucional sobre el cual los ciudadanos ya no deberian preocuparse. Y si éste fuera un mundo más justo, este mínimo no debería de ser el tema de la ley y la coerción. Tampoco deberíamos inflar los derechos humanos a un máximo porque encontraríamos que es sólo otra cubierta del liberalismo individualista al estilo occidental' ${ }^{7}$. Cuanto menos sea necesario insistir sobre los derechos humanos, tanto mejor. Que las declaraciones se esfumen. Que los tratados y las convenciones se vuelvan obsoletos. Dejemos que las cortes judiciales no debatan más este asunto. El mejor futuro para los derechos humanos es que se conviertan, de hecho, en la realidad mínima garantizada para todos.

Cuando privilegiamos así los derechos del pobre, estamos llevando los derechos humanos al mínimo que debieran ser: ¡aquello que es requerido por todos! Los derechos de la mayoría pobre no se convierten en una injusticia para unos pocos. Los derechos de los pobres no se convierten en la explotación, la persecución, la tortura, la desaparición, la ejecución sumaria de unos pocos. Al contrario, los derechos de los pobres forman la base de una comunidad humana para todos. Al insistir en los derechos de los pobres, no es necesario un conflicto ni dentro de la jerarquía de los derechos humanos ni entre las generaciones de derechos humanos.

El discurso de los derechos humanos debe comenzar con el derecho a la vida, el derecho precisamente de los pobres. "Esta es la intuición fundamental del tratamiento de los derechos humanos en América Latina: ver los derechos humanos desde el derecho a la vida de los pobres, y no a la inversa..." En términos cristianos, monseñor Romero enfatizó esto hace más de diez años cuando dijo: "En mi país se mata cruelmente. Los pobres están siendo asesinados, los campesinos tonurados, día tras día con la más extrema violencia. Es preciso defender lo mínimo que es el máximo don de Dios: la vida"'10.

La relación entre los derechos humanos y la teología de la liberación es la relación entre este mínimo y este máximo"l.

Los derechos humanos consideran la condición humana en términos de lo que es fundamental y esencialmente necesario, y no sujeto a ninguna negociación, para que la vida pueda ser vida, para que la vida pueda comenzar, crecer y desarrollarse en todas sus dimensiones. Lo mínimo. Lo menos que podemos y debemos hacer.

Pero desde el punto de vista de Dios, la vida es el regalo y lo es todo. La vida es la expresión del amor de Dios. El regalo de Dios para los pobres es la vida.

Tal vez la doctrina más conocida y citada de la teología de la liberación es la opción preferencial por los pobres. Sólo Dios puede ejercer realmente la opción 
preferencial por los pobres y al mismo tiempo, tratar a todos con justicia y con amor. Sólo Dios tiene el amor infinito para amar a los pobres preferencial, pero no exclusivamente y para tratar a cada hombre y mujer en la tierra como su único y amado hijo. Sólo Dios tiene la ilimitada imaginación para ver de antemano cómo una situación de violaciones sistemáticas de los derechos de los pobres (quienes son la mayoría, más de los dos tercios de la población de la tierra) puede desembocar en una sociedad de justicia, de seguridad y de paz. Pero el hecho de que nosotros no podamos ni imaginarlo ni reconciliar estos extremos, el hecho de que en nosotros mismos no podamos encontrar el amor suficiente, no nos excusa de la tarea que Dios nos ha dado, la tarea de luchar por la defensa de los derechos de los pobres.

La teología de la liberación tiene la tarea de amonizar y coordinar el máximo divino con el mínimo humano. La teología de la liberación esparce la luz de la revelación judía y cristiana (y por extensión la luz de toda revelación divina) sobre estos hechos inaguantables y que, sin embargo, son la realidad de la vida para la mayoria de la humanidad.

La teologfa de la liberación cobra sentido en lo que parece contradictorio e imposible, en lo que parece estar más allá de toda nuestra fuerza y de todos nuestros recursos. Porque la teología de la liberación esparce luz también sobre nuestra tarea de trabajar en los derechos humanos. Estamos todos llamados a defender el derecho a la vida, aun cuando ello nos traiga confrontación con los poderes del mundo y con las fuerzas que intentan aniquilar la vida.

Les estoy hablando prácticamente en el primer aniversario de la muerte de mis seis hermanos y de sus dos colaboradoras en la Universidad Centroamericana "José Simeón Cañas" (UCA), quienes fueron asesinados el 16 de noviembre de 1989, por miembros de la Fuerza Armada de El Salvador. Fueron asesinados por creer en los derechos humanos y en la opción preferencial por los pobres y por vivir su fe al máximo. Su vocación como seres humanos, como sacerdotes, como intelectuales, fue la de convertir esta verdad - la realidad de la vida y de la muerte para la gente de El Salvador- en la verdad y el sentido en la universidad y en la sociedad.

Uno no puede hablar sobre los derechos humanos sin hablar de una vocación y una misión. En la tradición cristiana -y en muchas otras también- dar la vida de uno por la vida de los pobres puede ser expresado en una sola palabra: amor. La defensa de la vida de los pobres es amor. La defensa de su vida, corriendo el riesgo y al precio de la vida propia, es amor hasta el límite divino. 


\section{Notas}

1. Ponencia tenida en la conferencia, Human Rights in the Twenty-First Century: A Global Challenge Conference, Benff, Alberte, Cenade, 9-12 de noviembre de 1990. Traducción de Emesto Buitrago. En el presente arúculo se ha mantenido el estilo propio de una conferencia.

2. Vice-recor de Proyección Social, y director del Instinlo de Derechos Humanos (IDHUCA), de la Universidad Centroamericana "Jost Simeón Caủas". San Salvador.

3. Ignacio Ellacuría, "Historización de los derechos humanos desde los pueblos oprimidos y las mayorfas populares", Esudios Centroamericanos 502 (agosto 1990), p. 590.

4. V. Ramaswamy, "A New Human Rights Consciousnes". IFDA Dossier 80 (January/March 1991), pp. 3-16.

5. "En 1990, más de la mitad de la población vivía en condiciones de pobreza, esto es, su ingreso familiar mensual no le permitía satisfacer sus necesidades básicas $y$, alrededor de un tercio de ella, estaba en simeción de extrema pobreza, esto es, no alcanzaba siquiera a cubrir la canasta bésica de alimentos." Centro de Información. Documentación y Apoyo a la Investigación (CIDAI). El Salvador, 1991.

6. United Nations Development Programme, Human Development Report 1990. New York: Oxford University Press, 1990, p. 185.

7. Cuando los derechos humanos se restringen a una visión de liberalismo se asume que "la concepción liberal de la libertad hace hincepie en que esta tiene por sujeto propio a cada uno de los individuos: cada una de las personas es la que puede ser libre y la libertad sólo se predica formalmente de las persones individuales. Liberalismo e individualismo parecen así reclamarse munamente". Ignacio Ellacuría, "En tomo al concepto y a la idea de liberación", Implicaciones sociales y polfricas de la teologla de la liberación, Madrid: Escuela de Eswdios Hispanoamericanos: Instituto de Filosofia, 1985, p. 99.

8. Tal conflicto pudiera ser tomado como una evidencia més de la "competencia" en el mercado dentro de una concepción estrechamente liberal de los derechos humanos, donde por ejemplo el derecho al medio ambiente sano (un derecho de la tercera generación) entra en conflicto con el derecho a la vida (primera generación) o al trabajo (segunda generación) de ciertas personas, grupos o clases.

9. Jon Sobrino. "Lo divino de luchar por los derechos humanos", Sal Terrae 10 (octubre 1984), p. 687, nota 4.

10. Ibid.

11. "AsI, por ejemplo, que la filosofía o la teologla no hablen de la violación de los derechos humanos, degrada la importancia de esta cuestion y por lo mismo contribuye a su más fácil violación; que la Iglesia como institución no lo haga, lleva al mismo efecto. Al contrario si la filosofía y la teología lo woman como punto relevante de la praxis social (expresión redundante), dan a esa realidad histórica una relevancia que de otro modo se mantendría disfrazada para conveniencia de las clases o grupos dominantes". Ignacio Ellacuría, "Función liberadora de la filosofia". Estudios Centroamericanos 435-436 (enero-febreto 1985), p. 58. 